\title{
Evolution of the Silicon Bottom Cell Photovoltaic Behavior during III-V on Si Multi-junction Solar Cells Production
}

\author{
E. García-Tabarés , T.J. Grassman , D. Martín , J. Carlin , I. Rey-Stolle, and S.A. Ringel
}

\begin{abstract}
The evolution of the Si bulk minority carrier lifetime during the heteroepitaxial growth of III-V on Si multijunction solar cell structures via metal-organic vapor phase epitaxy has been analyzed. Initially, the emitter formation produces important lifetime degradation. Nevertheless, a progressive recovery was observed during the growth of the metamorphic GaAsP/Si structure. A step-wise mechanism has been proposed to explain the lifetime evolution observed during this process. The initial lifetime degradation is believed to be related to the formation of thermally-induced defects within the Si bulk. These defects are subsequently passivated by fastdiffusing atomic hydrogen -coming from precursor (i.e. $\mathrm{PH}_{3}$ and $\mathrm{AsH}_{3}$ ) pyrolysis- during the subsequent III-V growth. These results indicate that the MOVPE environment used to create the III-V/Si solar cell structures has a dynamic impact on the minority carrier lifetime. Consequently, designing processes that promote the recovery of the lifetime is a must to support the production of high-quality III-V/Si solar cells.
\end{abstract}

Index Terms - Minority carrier lifetime, III-V on Si, MJSC, Si bottom cell.

\section{INTRODUCTION}

Within a III-V/Si multijunction solar cell, the minority carrier lifetime of the Si bottom cell is a key parameter, governing not only the photovoltaic $(\mathrm{PV})$ properties of the $\mathrm{Si}$ subcell itself, but also the entire multi-junction device [1]. It is well known that this parameter strongly depends on the thermal history and processing environment in which the $\mathrm{Si}$ cells are manufactured $[2,3]$. Therefore, it is important to fully understand the impact of the environment in which the III-V/Si structure is produced. Here we focus on metalorganic vapor phase epitaxy (MOVPE), an industry standard technique for III-V semiconductor growth.

Despite the achievement of high-quality III-V layers integrated on Si substrates [4-7], the impact of these steps on the $\mathrm{Si}$ bulk lifetime has not been explored to date. Accordingly, in this paper, the influence of the MOVPE environment on the photovoltaic properties of the bottom subcell base during the different steps followed for the formation of the III-V/Si multijunction solar cell (MJSC), similar to the one depicted in Figure 1, will be studied.

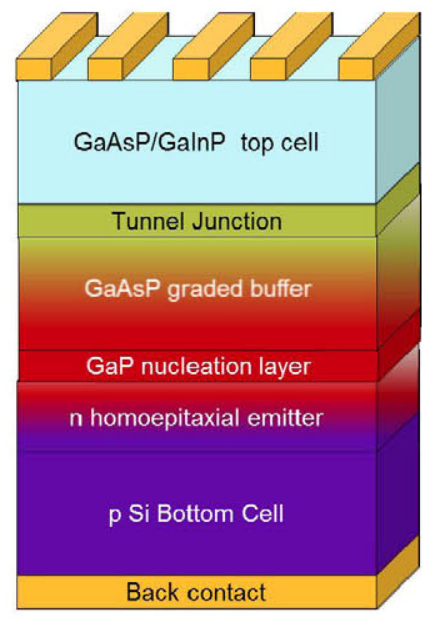

Fig. 1. Proposed III-V on Si multijunction solar cell structure.

Moreover, a theoretical study aimed to elucidate and predict the impact on device performance as a result of growth conditions and methods has been performed in order to improve the design of future processes.

\section{EXPERIMENTAL}

The evolution of the bulk Float zone (Fz) Si minority carrier lifetime throughout the growth process of the metamorphic III-V on Si structure has been assessed. The overall process used for the epitaxial III-V/Si and $\mathrm{Si}$ subcell is described elsewhere $[8,9]$ and is briefly summarized in Table I. To visualize the evolution of lifetime, a wide set of samples were grown, with interruptions at one of four different points in the process: 1) the formation of the emitter by $\mathrm{Si}$ homoepitaxial growth; 2) growth of the first layers of $\mathrm{GaP} ; 3$ ) growth of bulk $\mathrm{GaP}$ nucleation layer; and 4) growth of the GaAsP step-graded buffer.

Before performing minority carrier lifetime measurements, all epitaxial material was removed via etching in a $\mathrm{HCl}: \mathrm{HNO}_{3}$ solution. In addition, at least $1 \mu \mathrm{m}$ of Si surface material was stripped away for ensuring a clean surface. The etched sample was then passivated in a $0.05 \mathrm{M}$ quinhydrone-methanol solution bath [10]. 
TABLE I.

PROCESS DESCRIPTION AND AVERAGE MINORITY CARRIER LIFETIME FOR FZ Si WAFERS AFTER III-V HETEROEPITAXY

\begin{tabular}{|c|c|c|c|c|c|}
\hline Step & Structure & Precursors & Thermal process & $\left.\boldsymbol{\Delta n}_{(\mathbf{c m}} \mathbf{3}\right)$ & $\boldsymbol{\tau}_{\mathbf{b}}(\boldsymbol{\mu} \mathbf{s})$ \\
\hline 0 & Fz Si as-received & - & - & $10^{15}$ & 432 \\
\hline 1 & + Homoepitaxial Si emitter & $\mathrm{H}_{2}, \mathrm{SiH}_{4}$ & $180 \mathrm{~min} .760^{\circ} \mathrm{C}$ & $10^{14}$ & $<1$ \\
\hline 2 & $+\mathrm{GaP}$ nucleation & $\mathrm{H}_{2}, \mathrm{TBP}, \mathrm{TEGa}$ & $2.5 \mathrm{~min} 450^{\circ} \mathrm{C}$ & $10^{14}$ \\
\hline 3 & $+\mathrm{GaP}$ bulk & $\mathrm{H}_{2}, \mathrm{TBP}, \mathrm{TEGa}$ & $30 \mathrm{~min} .580^{\circ} \mathrm{C}$ & $10^{15}$ & 72 \\
\hline 4 & $+\mathrm{GaAsP}$ buffer & $\mathrm{H}_{2}, \mathrm{PH}_{3}, \mathrm{AsH}_{3}, \mathrm{TMGa}$ & $110 \mathrm{~min} .725^{\circ} \mathrm{C}$ & $10^{15}$ & 467 \\
\hline
\end{tabular}

As shown in Table I, the minority carrier lifetime suffers a reversible degradation-recovery process during the epitaxial growth process. The key result is that, while Si homoepitaxy yields a drastic lifetime reduction, it was found that the III-V epitaxy (Steps 2, 3 and 4) does exactly the opposite, providing an equally drastic overall lifetime recovery. Nonetheless, the observed recovery process is less straightforward. After Step 2 , the GaP nucleation step, the lifetime increased by approximately an order of magnitude (from $<1 \mu$ s to $25 \mu \mathrm{s}$ ), despite the very short growth duration (2.5 min.) and lowtemperature $\left(450^{\circ} \mathrm{C}\right)$. Continued "bulk" GaP MOVPE growth for $30 \mathrm{~min}$. at $550^{\circ} \mathrm{C}$ (Step 3) provides an additional improvement by about a factor of 3 . However, the most substantial and remarkable lifetime recovery -back to its asreceived value-, occurs in Step 4, the long (110 min.), hightemperature $\left(725^{\circ} \mathrm{C}\right) \mathrm{GaAs}_{\mathrm{y}} \mathrm{P}_{1-\mathrm{y}}$ buffer growth.

\section{DISCUSSION}

\section{A. Minority Carrier Lifetime Evolution}

Neglecting the small contribution of $\mathrm{SiH}_{4}$ to the process atmosphere, the homoepitaxial emitter growth is very similar to annealing under pure $\mathrm{H}_{2}$ (within a MOVPE environment), which has been previously reported to produce a rapid degradation of the $\mathrm{Si}$ lifetime [2]. In this work, after discarding a number of possibilities, three alternatives remained open to explain lifetime degradation: 1) the indiffusion of some lifetime-killing impurity associated to the MOVPE process (like $\mathrm{Zn}$, a typical p-type dopant used in MOVPE that could back-diffuse from the reactor vacuum system); 2) the in-diffusion of transition metals (like $\mathrm{Cu}, \mathrm{Fe}$, $\mathrm{Ni}$ ) coming from heated parts of the MOVPE reactor; or 3) the formation of crystal defects as a result of the thermal treatment of the wafer. However, the first possibility (i.e., the unwanted introduction of $\mathrm{Zn}$ or other impurity used in the III$\mathrm{V}$ MOVPE process) has been recently discarded since lifetime degradation has been found to be a bulk phenomenon rather than a surface phenomenon [11]. Moreover, this hypothesis was ruled out since the same lifetime degradation was observed for samples which were annealed in ultra-high vacuum, in a Molecular Beam Epitaxy (MBE) reactor, where $\mathrm{Zn}$ had never been used.
Accordingly, only the ultra-fast diffusion of a transition metal (most likely $\mathrm{Fe}$ ) yielding a uniform contaminant distribution across the whole wafer or the formation of crystal defects, remain as open possibility to explain lifetime degradation. Regarding Fe contamination, our measurements of injection-level dependent recombination lifetime after light soaking show odd results that cannot be explained by the models of dissociation of $\mathrm{FeB}$ pairs into $\mathrm{Fe}_{i}$ by strong illumination.[12] This suggests that either the influence of other recombination centers cannot be neglected or other factors - such as atomic $\mathrm{H}$ as will be commented below- are having a key role in the $\mathrm{FeB} \rightarrow \mathrm{Fe}_{\mathrm{i}}$ dissociation dynamics. Further investigations with DLTS are ongoing to clarify it.

Finally, another likely mechanism behind the lifetime degradation is that the thermal treatment experienced by samples leads to the formation of crystalline defects (either extrinsic or intrinsic), which act as recombination centers [13]. Examples of such extrinsic defects are the formation of complexes with low pre-existing concentrations of $\mathrm{C}$ and/or $\mathrm{O}$ (such as thermal donors) or extended defects (such as the well-known swirls); while point defects (e.g. in-diffused vacancies) are examples for intrinsic defects.

Nonetheless, a progressive lifetime recovery is observed during the III-V epitaxial steps. This recovery is consistent with a passivation mechanism where the previously formed recombination centers are effectively mitigated. The most likely source of this effect is $\mathrm{H}$ passivation through the indiffusion of atomic $H$ [11], which is an extremely fast interstitial diffuser in $\mathrm{Si}$ [14] capable of penetrating deep into the wafer at the process conditions employed during the III-V epitaxy steps (Steps 2-4).

To further investigate the likelihood of an atomic $\mathrm{H}$ passivation mechanism, a set of experiments were conducted, the results of which are presented in Table II. Here, $250 \mathrm{~nm}$ GaP-on-Si wafers were produced following Phases 1-3, as described previously, cleaved up into pieces, and subjected to a range of anneals (without growth) within the MOVPE reactor under different precursor ambient $\left(\mathrm{PH}_{3}\right.$ and $\left.\mathrm{AsH}_{3}\right)$ and temperatures (from $550^{\circ} \mathrm{C}$ to $725^{\circ} \mathrm{C}$ ). In this sense, by increasing the annealing temperature, a more effective pyrolysis of the corresponding hydride is expected, and consequently higher doses of $\mathrm{H}$ will be available. The as- 
TABLE II

AVERAGE MINORITY CARRIER LIFETIME FOR CZ SI WAFERS AFTER III-V HETEROEPITAXY

\begin{tabular}{|c|c|c|c|c|}
\hline Sample & Thermal process & Precursors & $\boldsymbol{\Delta n}\left(\mathbf{c m}^{-3}\right)$ & $\tau_{\mathbf{b}}(\boldsymbol{\mu s})$ \\
\hline A & - & - & $10^{15}$ & 444 \\
\hline B & $30 \mathrm{~min} .550^{\circ} \mathrm{C}$ & $\mathrm{H}_{2}, \mathrm{TBP}, \mathrm{TEGa}$ & $10^{14}$ & 40 \\
\hline C & $90 \mathrm{~min} .725^{\circ} \mathrm{C}$ & $\mathrm{H}_{2}, \mathrm{PH}_{3}$ & $10^{15}$ & 475 \\
\hline D & $90 \mathrm{~min} .650^{\circ} \mathrm{C}$ & $\mathrm{H}_{2}, \mathrm{PH}_{3}$ & $10^{15}$ & 165 \\
\hline E & $90 \mathrm{~min} .650^{\circ} \mathrm{C}$ & $\mathrm{H}_{2}, \mathrm{AsH}_{3}$ & $10^{15}$ & 336 \\
\hline F & $90 \mathrm{~min} .600^{\circ} \mathrm{C}$ & $\mathrm{H}_{2}, \mathrm{AsH}_{3}$ & $10^{15}$ & 370 \\
\hline G & $90 \mathrm{~min} .550^{\circ} \mathrm{C}$ & $\mathrm{H}_{2}, \mathrm{AsH}_{3}$ & $10^{15}$ & 279 \\
\hline
\end{tabular}

grown material (i.e. unannealed) is denoted as sample B. In this case, Si substrates used were high-quality Czochralski $(\mathrm{Cz})$ wafers, with the same nominal doping and resistivity, as well as a similar as-received minority carrier lifetime (sample A), as the float-zone wafers used in the prior measurements.

The item of note is the result observed for Sample C, which received a $90 \mathrm{~min} .725^{\circ} \mathrm{C}$ anneal in $\mathrm{PH}_{3}$. This anneal was found to provide more than an order of magnitude increase in the lifetime, yielding a recovery back to (and even slightly higher than) the as-received value for the $\mathrm{Cz}$ substrate, similar to that seen with the Fz-Si after Step 4 growth (see Table I). First, this sample, along with Samples A and $\mathrm{B}$, suggest no impact of the wafer type ( $\mathrm{Cz}$ versus $\mathrm{Fz}$ ) on the lifetime degradation and the recovery mechanisms for this process. Second, and more importantly, this result supports the conclusion of H-passivation as the source of lifetime recovery. Previous investigation of potential $\mathrm{P}$ diffusion into $\mathrm{Si}$ across the $\mathrm{GaP} / \mathrm{Si}$ interface via annealing under these same conditions $\left(725^{\circ} \mathrm{C}, \mathrm{PH}_{3} / \mathrm{H}_{2}\right.$ ambient, $120 \mathrm{~min}$.) revealed no appreciable diffusion profile, as measured by SIMS [8], leaving H-passivation as the only likely contender. Consistent with the hypothesis of lifetime recovery due to atomic $\mathrm{H}$ passivation and reduced pyrolysis kinetics of the group- $\mathrm{V}$ hydrides at lower temperatures (thus yielding a lower dose of atomic $\mathrm{H}$ ), is the fact that when decreasing the $\mathrm{PH}_{3}$ annealing temperature from $725^{\circ} \mathrm{C}$ to $650^{\circ} \mathrm{C}$ (Sample D) the degree of lifetime recovery is also reduced.

Elucidation of whether this $\mathrm{PH}_{3}$-based recovery is limited by a lack of available atomic $\mathrm{H}$ or the result of the lower temperature is not possible due to the limited range of $\mathrm{PH}_{3}$ flows available in the MOVPE reactor used for this work. Therefore, to further examine this effect, an $\mathrm{AsH}_{3}$ anneal under identical conditions, Sample E $\left(650^{\circ} \mathrm{C}, 90 \mathrm{~min}\right.$.), was also performed. The $\mathrm{AsH}_{3}$ anneal resulted in a $\sim 8 \times$ increase in lifetime over the initial value, double which observed under $\mathrm{PH}_{3}$ (Sample D). In fact, a similar degree of recovery was observed for $\mathrm{AsH}_{3}$ based anneals all the way down to $550^{\circ} \mathrm{C}$. At such lower temperatures the likelihood of any group- $\mathrm{V}$ diffusion into the $\mathrm{Si}$ is effectively eliminated, further supporting the H-passivation mechanism.

The difference in magnitude of recovery observed for the two different species at $650^{\circ} \mathrm{C}$ is worth some examination. Since these anneals were completed at the same temperature, the difference suggests that the passivation is not limited by temperature but rather the availability of atomic $\mathrm{H}$, which is likely related to the relative pyrolysis kinetics and/or thermodynamics of the two hydride species. That is, $\mathrm{AsH}_{3}$ dissociates at the surface more readily than $\mathrm{PH}_{3}[15]$ due to its reduced molecular bond strength; $\mathrm{AsH}_{3}\left(\mathrm{H}_{2} \mathrm{As}-\mathrm{H}\right)$ has a significantly lower bond dissociation energy (for removal of the first $\mathrm{H}), 3.31 \mathrm{eV}$, versus that of $\mathrm{PH}_{3}\left(\mathrm{H}_{2} \mathrm{P}-\mathrm{H}\right), 3.64 \mathrm{eV}$ [16]. Based on a simple thermal Boltzmann analysis, this would suggest a difference in atomic $H$ supply from the two hydride species of two to three orders of magnitude for the range of annealing temperatures examined here, reasonably consistent with the difference in lifetime recovery observed for the $\mathrm{AsH}_{3}$ (Sample E) versus the $\mathrm{PH}_{3}$ (Sample D) annealing at $650{ }^{\circ} \mathrm{C}$. This same analysis also suggests strong temperature dependence for the supply of atomic $\mathrm{H}$, and thus lifetime recovery, which would be consistent with the behavior observed for the $\mathrm{PH}_{3}$ annealing at $725^{\circ} \mathrm{C}$ and $650^{\circ} \mathrm{C}$. Of course, such a simplistic analysis ignores the more complex chemical realities in such a reactive system -for example, the detailed reaction pathways on the $\mathrm{GaP}$ and $\mathrm{GaAs}_{\mathrm{y}} \mathrm{P}_{1-\mathrm{y}}$ surfaces of interest (as opposed to mere thermal "cracking") will strongly impact the actual reaction/dissociation kinetics- as evidenced by the relative lack of temperature dependence of the $\mathrm{AsH}_{3}$ anneals (Samples E - G). It is also worth noting that a weak trend in the $\mathrm{AsH}_{3}$ could exist, but is obscured by small errors in the lifetime measurement due to, for example, the quality of the quinhydrone surface passivation, although care was taken to ensure that all samples received identical preparation. Of note is the fact that the $\mathrm{AsH}_{3}$ anneals were found to cause the GaP surface to roughen significantly, which was not observed for $\mathrm{PH}_{3}$ or even pure $\mathrm{H}_{2}$ annealing and is presumably due to As-P displacement. The roughening 
a)

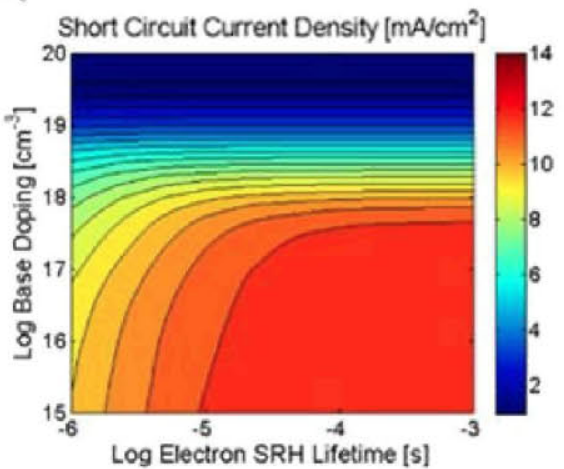

b)

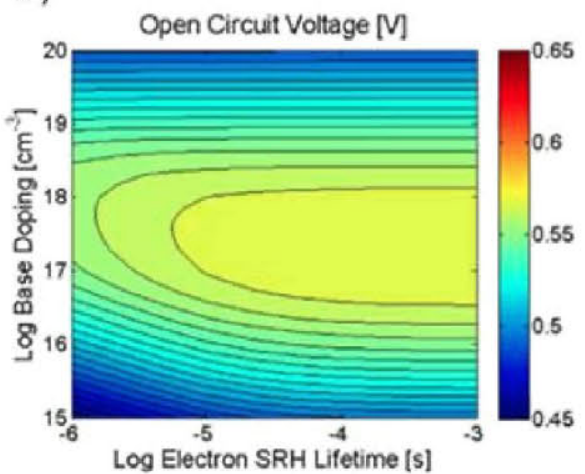

c)

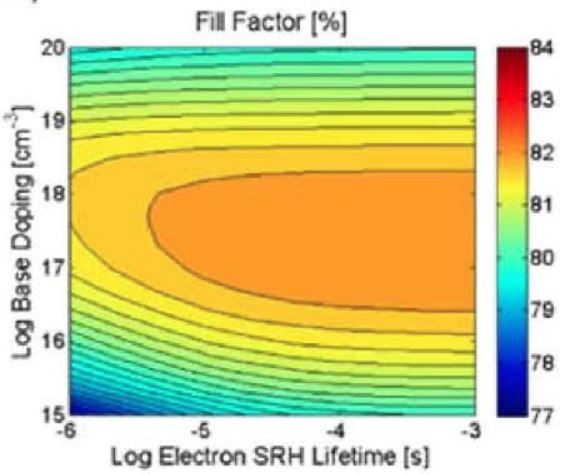

Fig. 2. False color maps for solar cell parameters as a function of base doping and minority carrier (electron) lifetime for the "lower-limit" scenario for the bottom subcell (i.e. no BSF and GaP/Si IRV of $10^{6} \mathrm{~cm} / \mathrm{s}$ ). (a) $J_{S C}$, (b) $V_{O C}$, (c) $F F$.

a)

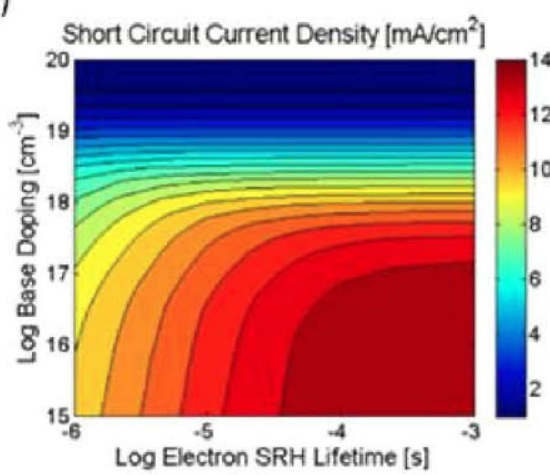

b)

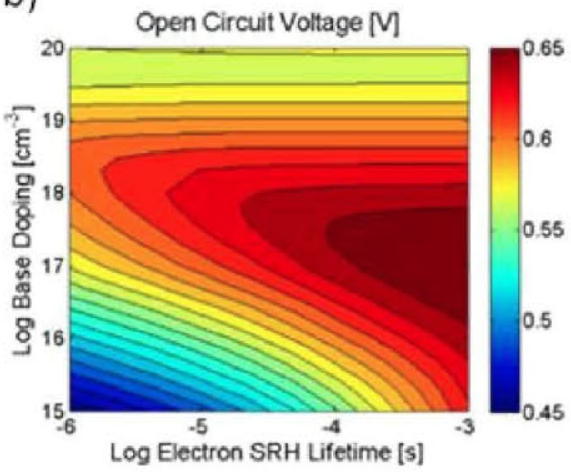

c)

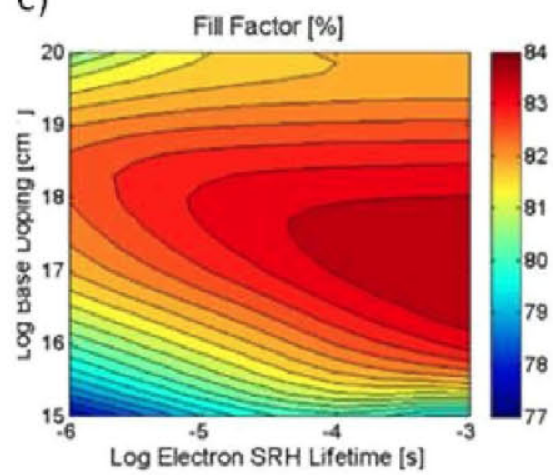

Fig. 3. False color maps for solar cell parameters as a function of base doping and minority carrier (electron) lifetime for an optimistic scenario for the bottom subcell (i.e. good BSF and GaP/Si IRV of $10^{4} \mathrm{~cm} / \mathrm{s}$ ). (a) $J_{S C}$; (b) $V_{O C}$; (c) $F F$.

effect was also found to track with increasing annealing temperatures; $725^{\circ} \mathrm{C} \mathrm{AsH}_{3}$ annealing effectively resulted in the complete decomposition of the GaP film (thus its lack of inclusion here). As such, it may be possible that the excess strain in the GaP had some secondary impact on the underlying $\mathrm{Si}$.

\section{B. Lifetime Impact on Solar Cell Performance}

The lifetime evolution process previously described is expected to have wide-reaching consequences for III-V/Si PV. Accordingly, with the aim of quantifying the effect of these processes on the bottom cell performance, the PV performance metrics (i.e. short circuit current density, open circuit voltage and fill factor) have been simulated for a $\mathrm{Si}$ subcell in a $\mathrm{GaAsP} / \mathrm{GaP} / \mathrm{Si}$ structure, under 1 sun $\mathrm{AM} 1.5 \mathrm{G}$ illumination and as a function of the minority carrier lifetime [11]. For a better assessment of the lifetime effect on the $\mathrm{Si}$ bottom cell, two possible scenarios have been considered: a "lower-limit" (high SRV) scenario and a more optimistic (low SRV) scenario.

Firstly, a "lower-limit" scenario was simulated where surfaces/interfaces with high recombination velocity - i.e. no $\mathrm{BSF}$ and a GaP/Si interface recombination velocity (IRV) of
$10^{6} \mathrm{~cm} / \mathrm{s}-$ were considered. Contour plots for this simulation series are presented in Figure 2. Correspondingly, Table III shows the evolution of Si bulk lifetime during the growth of the III-V structure (according to Table I) and its simulated impact on the bottom cell performance for this scenario, where a highly recombining rear surface has been considered. Parameters in the table were calculated for a base doping of $2 \cdot 10^{15} \mathrm{~cm}^{-3}$.

As expected, the results presented in Table III show that the degradation in bulk minority carrier lifetime that occurs during the growth of the homoepitaxial Si emitter does have a deleterious effect on all of the performance metrics of the $\mathrm{Si}$ bottom cell, as determined via the low open circuit voltage $\left(V_{\mathrm{OC}}\right)$ and short circuit current $\left(J_{\mathrm{SC}}\right)$ values; the latter is particularly important due to current-matching requirements, wherein poor bottom cell $J_{S C}$ will limit the performance of the entire dual junction solar cell.

The partial recovery that takes place during the growth of the GaP nucleation layer slightly improves the situation, which then stays virtually unchanged after the growth of the GaAsP buffer. This lack of significant improvement of $J_{\mathrm{SC}}$, $V_{\mathrm{OC}}$ and $F F$, despite the fact that minority carrier lifetime improves by a factor 8 , is a direct result of the lack of efficient passivation of both the front and back Si surfaces. As 
such, the cell is being limited by issues other than the minority carrier lifetime. Therefore, while the design of a careful process to recover (or maintain) bulk lifetime to the level of as-received wafers is important, it does not necessarily pay back in the form of higher efficiencies if the surface/interface recombination velocities are too high.

TABLE III

Simulated Bottom Subcell Electrical Parameters For a LOWER-LIMIT SCENARIO

\begin{tabular}{|c|c|c|c|c|}
\hline Step & $\begin{array}{c}\tau_{\mathbf{b}} \\
(\boldsymbol{\mu s})\end{array}$ & $\begin{array}{c}\boldsymbol{J}_{\mathbf{S C}} \\
\left(\mathbf{m A} / \mathbf{c m}^{2}\right)\end{array}$ & $\begin{array}{c}\boldsymbol{V}_{\mathbf{O C}} \\
(\mathbf{m V})\end{array}$ & $\begin{array}{c}\text { FF } \\
(\boldsymbol{\%})\end{array}$ \\
\hline Emitter growth & 1 & 10.18 & 475 & 78.74 \\
\hline GaP nucleation & 25 & 12.04 & 512 & 80.34 \\
\hline GaP bulk & 72 & 12.56 & 517 & 80.54 \\
\hline GaAsP buffer & 467 & 12.64 & 519 & 80.65 \\
\hline
\end{tabular}

Figure 3 presents simulated results from a more optimistic scenario. In this case, better surfaces were considered via the introduction of a full-area BSF ( $1 \mu \mathrm{m}$ thick and doped at a theoretically ideal $\mathrm{N}_{\mathrm{A}}=10^{20} \mathrm{~cm}^{-3}$ ) and reducing the $\mathrm{GaP} / \mathrm{Si}$ IRV down to $10^{4} \mathrm{~cm} / \mathrm{s}$. For the purpose of comparison, the emitter doping and thickness are the same as in the previous simulations (Table III). Accordingly, Table IV presents the performance metrics of the $\mathrm{Si}$ bottom cell for the same lifetime values under the optimistic scenario. Parameters in the table were calculated for a base doping of $2 \cdot 10^{15} \mathrm{~cm}^{-3}$.

TABLE IV

Simulated BotTom Subcell Electrical Parameters for an OptIMISTIC SCENARIO

\begin{tabular}{|c|c|c|c|c|}
\hline Step & $\begin{array}{c}\tau_{\mathbf{b}} \\
(\boldsymbol{\mu s})\end{array}$ & $\begin{array}{c}\boldsymbol{J}_{\text {SC }} \\
\left(\mathbf{m A} / \mathbf{c m}^{2}\right)\end{array}$ & $\begin{array}{c}\boldsymbol{V}_{\text {OC }} \\
(\mathbf{m V})\end{array}$ & $\begin{array}{c}\mathbf{F F} \\
(\%)\end{array}$ \\
\hline Emitter growth & 1 & 10.19 & 475 & 78.75 \\
\hline GaP nucleation & 25 & 13.02 & 531 & 80.68 \\
\hline GaP bulk & 72 & 13.94 & 558 & 81.13 \\
\hline GaAsP buffer & 467 & 14.27 & 610 & $\mathbf{8 1 . 1 9}$ \\
\hline
\end{tabular}

Table IV shows that moving to the optimistic scenario not only yields a significant improvement of the electrical parameters (as a result of having lower recombination losses at both surfaces), but it also indicates that $J_{\mathrm{SC}}$ and $V_{\mathrm{OC}}$ are no longer limited by the recombination at the surfaces, but rather by the minority carrier lifetime in the Si bulk. Accordingly, unlike the pessimistic scenario, any processes contributing to a larger recovery of such minority carrier lifetime would produce the corresponding increase in the PV parameters of the solar cells. As an example, the increase of the bulk lifetime that is produced during the growth of the GaAsP buffer layer in our samples is shown to have a deep impact on the bottom cell electrical performance, especially on its $V_{O C}$.
Therefore, it is important to note that despite the evolution of the bulk lifetime during the III-V epitaxy, which ultimately provides full recovery, the design of the $\mathrm{Si}$ subcell is nonetheless of major relevance. Of course, this is not a surprise, as the sensitivity of Si solar cells to poor surface passivation is well-known. However, provided proper design and execution of passivating structures at the rear (BSF) and front $(\mathrm{GaP} / \mathrm{Si})$, the evolution of the minority carrier lifetime then becomes key to not only the Si subcell performance, but the performance of the multijunction structure as a whole.

\section{SUMMARY}

The evolution of the Si bulk lifetime during key phases in the fabrication of a III-V-on-Si epitaxial structure has been analyzed. A two order of magnitude reduction in bulk $\mathrm{Si}$ lifetime during the emitter formation, followed by a complete recovery was observed to result from the sequential growth of the metamorphic GaAsP/Si structure. The primary source for degradation is attributed to the formation of a uniform distribution of recombination centers across the wafer. The precise nature of such recombination centers has not been unequivocally determined yet. The possibilities that remain open are the contamination by transition metals (i.e. Fe) or the formation of crystalline defects, such as swirls, point defects or complexes with typical pre-existing atoms of $\mathrm{C}$ and/or $\mathrm{O}$, in both cases during the MOVPE process. However, the recovery observed during subsequent III-V epitaxy is consistent with $\mathrm{H}$ passivation of these defects, with the $\mathrm{H}$ being supplied through the pyrolysis of the precursors, especially the group- $\mathrm{V}$ hydrides $\left(\mathrm{AsH}_{3}\right.$ and $\left.\mathrm{PH}_{3}\right)$.

The reported evolution of the minority carrier lifetime reveals that some steps of the epitaxy process have deleterious effects on the lifetime that, if not recovered, will have a detrimental impact on the $\mathrm{Si}$ bottom cell performance. Therefore, designing processes that promote the recovery of the lifetime during the growth of the III-V structure is a must to support the production of high-performance multi-junction III-V/Si solar cells. However, if the minimization of recombination losses at $\mathrm{Si}$ interfaces is not addressed, any gain in minority carrier lifetime may not translate into any improvement of the solar cell performance.

\section{ACKNOWLEDGEMENTS}

Some of the experiments in this work were carried out during a research stay of Ms. Elisa García-Tabarés at the Nanotech West Lab of The Ohio State University. We acknowledge the strong support of the staff at OSU and the financial support of the Universidad Politécnica de Madrid for her stay. We also acknowledge Fundación Iberdrola for their financial support within the program "Ayudas a la Investigación en Energía y Medioambiente". This work was supported by FP7 Program of the European Union through 
project NGCPV (283798), by the Spanish Ministerio de Economía y Competitividad through project with reference TEC2012-37286. It was also supported by the Department of Energy under the FPACE program (DE-EE0005398) and the Ohio Office of Technology Investment Third Frontier program.

\section{REFERENCES}

[1] D. Martin, et al., "Numerical simulation and experimental facts about bottom-cell optimization for III-V on silicon multijunction solar cells," in IEEE 39th Photovoltaic Specialists Conference (PVSC), Tampa, Florida, USA, 2013, pp. 0873-0878.

[2] E. García-Tabarés and I. Rey-Stolle, "Impact of metalorganic vapor phase epitaxy environment on silicon bulk lifetime for III-V-on-Si multijunction solar cells," Solar Energy Materials and Solar Cells, vol. 124, pp. 17-23, 2014.

[3] A. Ulyashin, et al., "Effective lifetime of minority carriers in silicon: the role of heat- and hydrogen plasma treatments," in 8th High Purity Silicon Conference, Oslo, Norway, 2004, pp. 334-345.

[4] J. F. Geisz, et al., "Lattice-mismatched GaAsP Solar Cells Grown on Silicon by OMVPE," in Photovoltaic Energy Conversion, Conference Record of the 2006 IEEE 4th World Conference on, 2006, pp. 772-775.

[5] T. J. Grassman, et al., "Characterization of metamorphic $\mathrm{GaAsP} / \mathrm{Si}$ materials and devices for photovoltaic applications," IEEE Transactions on Electron Devices, vol. 57, pp. 3361-3369, 2010.

[6] K. Hayashi, et al., "MOCVD growth of GaAsP on Si for tandem solar cell application," in Proceedings of the 24th IEEE Photovoltaics Specialist Conference, Hawaii,USA, 1994, pp. 1890-1893
[7] T. Roesener, et al., "MOVPE growth of III-V solar cells on silicon in $300 \mathrm{~mm}$ closed coupled showerhead reactor," in 25th European Photovoltaic Solar Energy Conf. and Exhibition, Valencia, Spain, 2010, pp. 964 - 968.

[8] T. J. Grassman, et al., "MOCVD-grown GaP/Si subcells for integrated III-V/Si multijunction photovoltaics," IEEE Joumal of Photovoltaics, , vol. 4, pp. 972-980, 2014.

[9] T. J. Grassman, et al., "Nucleation-related defect-free $\mathrm{GaP} / \mathrm{Si}(100)$ heteroepitaxy via metal-organic chemical vapor deposition," Applied Physics Letters, vol. 102, pp. 1421021 - 1421024, 2013.

[10] H. Takato, et al., "Surface passivation of silicon substrates using quinhydrone/methanol treatment," in Proceedings of 3 rd World Conference on Photovoltaic Energy Conversion Osaka, Japan, 2003, pp. 1108-1111 Vol.2.

[11] E. García-Tabarés, et al., "Evolution of Silicon Bulk Lifetime during III-V-on-Si Multijunction Solar Cell Epitaxial Growth," Progress in Photovoltaics: Research and Applications, vol. To be published, 2015.

[12] D. H. Macdonald, et al., "Iron detection in crystalline silicon by carrier lifetime measurements for arbitrary injection and doping," Journal of Applied Physics, vol. 95, pp. 1021-1028, 2004.

[13] E. Susi, "Recombination mechanisms in crystalline silicon: bulk and surface contributions," International Journal of Photoenergy, vol. 1, pp. 1-9, 1999.

[14] H. Bracht, "Diffusion mechanisms and intrinsic pointdefect properties in silicon," MRS bulletin, vol. 25, pp. 2227,2000 .

[15] G. B. Stringfellow, Organometallic Vapor-Phase Epitaxy: Theory and Practice. San Diego \& London: Academic Press, Inc., 1989.

[16] Y.-R. Luo and J.-P. Cheng, "Bond dissociation energies in polyatomic molecules," in CRC Handbook of Chemistry and Physics, W. M. Haynes, Ed., ed Boca Raton, FL, USA, 2014-2015. 